Pres. 1996 Nuclear Science Symp., CONF-96/123--1

Anabeim, CA, 6.9 November 1996

$B N L-63019$

\title{
STUDY OF BULK DAMAGE IN HIGH RESISTIVITY SILICON DETECTORS IRRADIATED BY HIGH DOSE ${ }^{60} \mathrm{Co} \gamma$-RADIATION
}

\author{
Z. $\mathrm{Li}$ and C. J. $\mathrm{Li}^{+}$ \\ Brookhaven National Laboratory \\ Upton, NY 11973-5000
}

April, 1996

\section{DISCLAIMER}

This report was prepared as an account of work sponsored by an agency of the United States Government. Neither the United States Government nor any agency thereof, nor any of their employees, makes any warranty, express or implied, or assumes any legal liability or responsibility for the accuracy, completeness, or usefulness of any information, apparatus, product, or process disclosed, or represents that its use would not infringe privately owned rights. Reference herein to any specific commercial product, process, or service by trade name, trademark, manufacturer, or otherwise does not necessarily constitute or imply its endorsement, recommendation, or favoring by the United States Government or any agency thereof. The views and opinions of authors expressed herein do not necessarily state or reflect those of the United States Government or any agency thereof.

+ Permanent address: Inst. of Semiconductors, Chinese Academy of Sciences, Beijing, 100083, China

*This research was supported by the U. S. Department of Energy: Contract No. DE-AC02-76CH00016

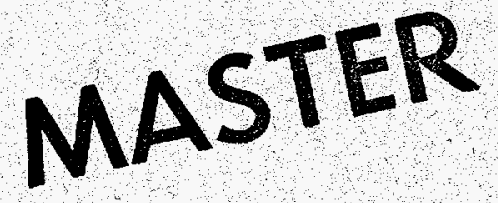




\section{DISCLAMMER}

Portions of this document may be illegible in electronic image products. Images are produced from the best available original document. 


\section{Study of Bulk Damage in High Resistivity Silicon Detectors Irradiated by High Dose of ${ }^{\infty}$ Co rRadiation* \\ Z. $\mathrm{Li}$ and C.J. Li \\ Brookhaven National Laboratory \\ Upton, NY 11973, USA}

Abstract
High dose (>200 Mrad) $\gamma$-radiation induced displacement damage (or bulk damage) in high resistivity $(6-10 \mathrm{k} \Omega-\mathrm{cm})$ silicon detectors has been studied. It has been found that detector bulk leakage current increases with $\gamma$ dose at a rate of $3.3 \times 10^{-7} \mathrm{~A} / \mathrm{cm}^{3} / \mathrm{Mrad}$. This introduction rate of bulk leakage current makes the introduction of generation centres by 210 Mrad of $\gamma$-radiation comparable to that by $1 \times 10^{12} \mathrm{n} / \mathrm{cm}^{2}$ of neutron radiation. Significant carrier removal (or donor removal), about $100 \%$, was found in detectors irradiated to $215 \mathrm{Mrad}$. Space charge sign inversion (SCSI) (or "type inversion") was observed in detectors irradiated to $\geq 215$ Mrad using transient current technique (TCT). As many as seven deep levels have been observed by current deep level transient spectroscopy (I-DLTS). There was little or no annealing (or reverse annealing) for detectors irradiated to $215 \mathrm{Mrad}$. Some annealing for detectors irradiated to 500 Mrad have been observed.

\section{SUMMARY \\ I. INTRODUCTION}

Recently, the observed abnormal annealing behavior (or "reverse annealing", "anti-annealing", which is the effect of the increase of the net, acceptor-type effective concentration of space charges ( $N_{\text {eff }}$ ) with annealing time) of neutron irradiated high resistivity silicon detectors has prompted renewed interest in microscopic defect measurements and identifications in such detectors [1-6]. The goal is to find the defect generation mechanism responsible for and/or, a model that describes, this abnormal annealing effect. This in turn will help one to find the way to develop radiation-hard detectors via impurity engineering. Experimental evidence to date has suggested a model involving the defect clusters for the generation of deep acceptor charges in the space charge region (SCR) [7-8], which attributes the abnormal annealing as the direct result of the breaking-up of defect clusters into ionized acceptor-like single defects.

If defect clusters are the main cause for the abnormal annealing effect observed in neutron irradiated high resistivity silicon detectors, then one expects to see little or no such abnormal annealing effect in $\gamma$ irradiated high resistivity silicon detectors. This is because that $\gamma$ radiation only produces random single defects (no defect clusters) in silicon. Study of $\gamma$-irradiated high resistivity silicon detectors and the subsequent annealing behavior can be therefore important in resolving the defect cluster issue in neutron irradiated detectors.

\section{EXPERIMENTAL}

Planar $\mathrm{Al} / \mathrm{p}^{+} / \mathrm{n}^{+} \mathrm{n}^{+} / \mathrm{Al}$ silicon detectors with original resistivity of $6-10 \mathrm{k} \Omega-\mathrm{cm}$ (n-type) were fabricated at Brookhaven National Laboratory (BNL). Each detector is 0.1 $\mathrm{cm}^{2}$ in area and $368 \mu \mathrm{m}$ in thickness. Detectors were irradiated with a calibrated $15 \mathrm{kCi}{ }^{80} \mathrm{Co}$ source at BNL.

The experiments included traditional capacitance-reverse bias $(C-V)$ and current-reverse bias $(I-V)$ characteristics to monitor detector electrical degradation; measurements of radiation induced deep levels using I-DLTS and TSC with optical defect filling techniques [5], and applications of transient current/transient charge techniques (TCT/TChT) using laser pulse excitation of non-equilibrium free carriers to determine both the magnitude and sign of space charge concentration $N_{\text {eff }}$ [9-10].

Elevated temperature annealing (ETA) was performed or irradiated detectors in $\mathrm{N}_{2}$ ambient with fast heating time (about 10-15 seconds) to the annealing temperature $T_{0}$ and fast cooling time (about 5-10 seconds) to the RT. The temperature stability is within $\pm 1.0{ }^{\circ} \mathrm{C}$. Electrical measurements $(C-V, I-V), \mathrm{TCT} / \mathrm{TChT}$ measurements (I-t) current-time/ $Q$ - $V:$ charge-reverse bias), and defect measurements (I-DLTS, TSC) were carried out before ETA and after each ETA. Measurements of $C \cdot V, I-V$, and TCT/TChT were done at RT.

\section{RESULTS AND DISCUSSIONS}

The $I-V$ and $C-V$ characteristics of a detector before and after $\gamma$ irradiation are shown in Fig. 1 . It is clear from the $C-V$ curves that the detector was fully depleted at about 45 volts (full depletion voltage $V_{d}=45$ volts). After a $\gamma$ irradiation of $215 \mathrm{Mrad}, V_{d}$ decreased to about 10 volts. A $\gamma$ irradiation of $501 \mathrm{Mrad}$ however, made $V_{d}$ to increase to about 110 volts. This behavior is similar to that observed in neutron irradiated detectors before and after SCSI.

The detector leakage current clearly increases with $\gamma$ dose (Fig. 1a). A pinch-off effect near the full depletion bias was observed in irradiated detectors. This is due to the fact that SCSI caused the junction switching side from near the $\mathrm{p}^{+}$ contact before irradiation to near the $\mathrm{n}^{+}$contact after irradiation. At the pinch-off, all the surface currents, including currents from the damaged edges on the $n^{+}$side, are cut off by the guard ring (GR). The current measured beyond the pinch-off is the true bulk current. From Fig. 1a, one can 
get a bulk leakage coefficient for ${ }^{\infty} \mathrm{Co} \gamma$-radiation of the value of $3.34 \times 10^{-7} \mathrm{~A} / \mathrm{cm}^{8} / \mathrm{Mrad}$. The introduction of generation centers by $210 \mathrm{Mrad}{ }^{\infty} \mathrm{Co} \gamma$-radiation is about the same as that by $1 \times 10^{12} \mathrm{n} / \mathrm{cm}^{2}$ fast neutrons (1 $\mathrm{MeV}$ ).

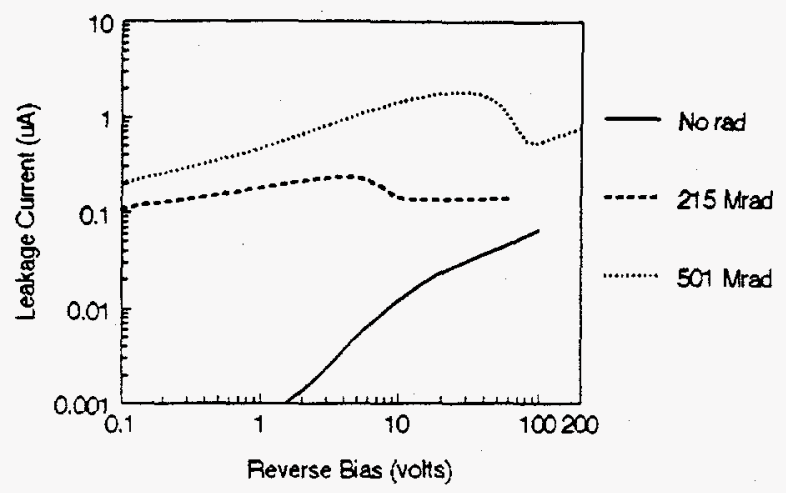

a)

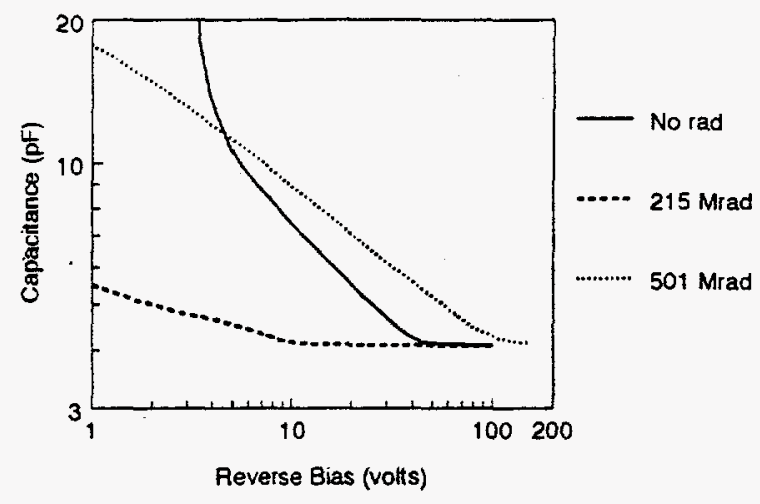

b)

Fig. $1 I-V$ a) and C-V curves b) for a detector before and after $\gamma$ irradiation. Guard ring was grounded in all measurements (GRG).

The SCSI can be readily seen in laser light induced current shapes using TCT, as shown in Fig. 2. Fig. 2a displays the hole current shapes (laser light on the $\mathrm{n}^{+}$side) for a control detector (no irradiation). It is clear that holes drift from low electric field to high electric field, indicating that the junction is on the $\mathrm{p}^{+}$side.

After a radiation of $215 \mathrm{Mrad}$, the sign of the current shape top changes from positive (Fig. $2 \mathrm{a}, N_{\text {eff }}=4 \times 10^{11} / \mathrm{cm}^{3}$ ) to negative (Fig. $2 \mathrm{~b}, N_{\text {eff }}=-1 \times 10^{11} / \mathrm{cm}^{3}$ ), indicating a SCSI from positive to negative. The carrier removal (or donor removal) is about $100 \%$ at $215 \mathrm{Mrad}$. The junction is now located near the $\mathrm{p}^{+}$contact. Further irradiation will make the space charge more negative due to acceptor creation, as shown in Fig. $2 \mathrm{c}\left(N_{\text {eff }}=-1.1 \times 10^{12} / \mathrm{cm}^{3}\right)$. The acceptor creation rate is about $\mathrm{b}=1 \times 10^{12} / \mathrm{cm}^{3} / 500 \mathrm{Mrad}=2 \times 10^{9} / \mathrm{cm}^{3}$ $/$ Mrad. This $\gamma$ irradiation induced SCSI is very similar that caused by neutron irradiation.

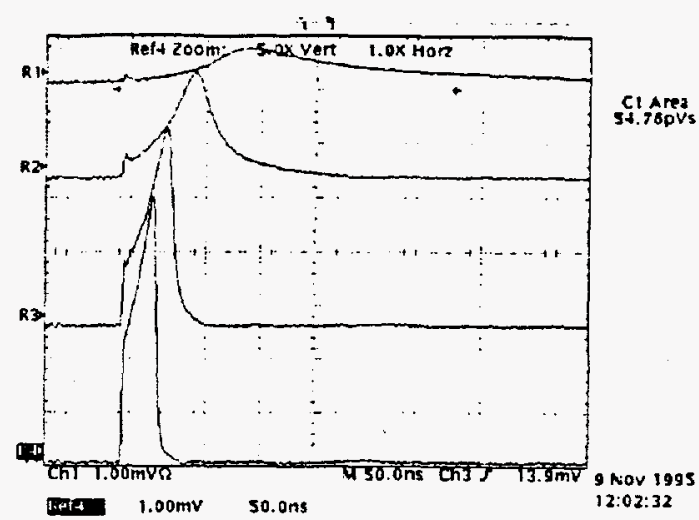

a) Control sample (NO6-130).

R1: $40 \mathrm{~V} ;$ R2: $50 \mathrm{~V}$; R3: $70 \mathrm{~V}$; R4: $100 \mathrm{~V}$

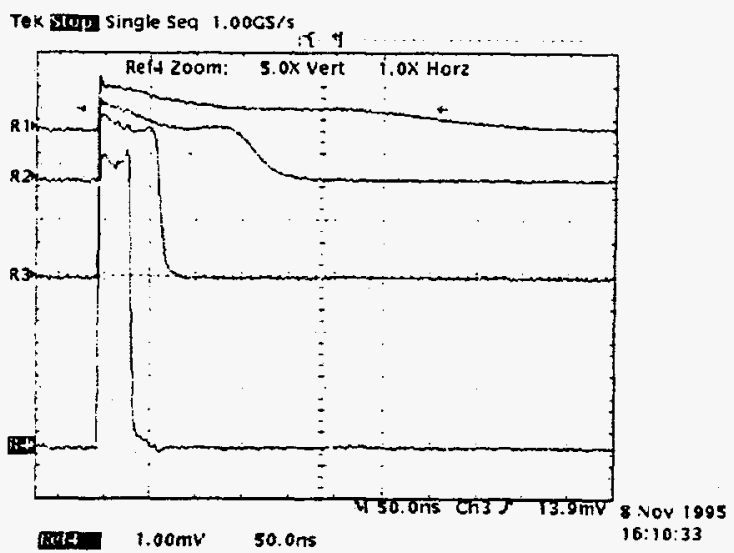

b) $215 \mathrm{Mrad}$ (11/3/95) (Sample NO6-109).

R1: $10 \mathrm{~V} ; \mathrm{R} 2: 20 \mathrm{~V} ; \mathrm{R3}: 50 \mathrm{~V} ; \mathrm{R} 4: 100 \mathrm{~V}$

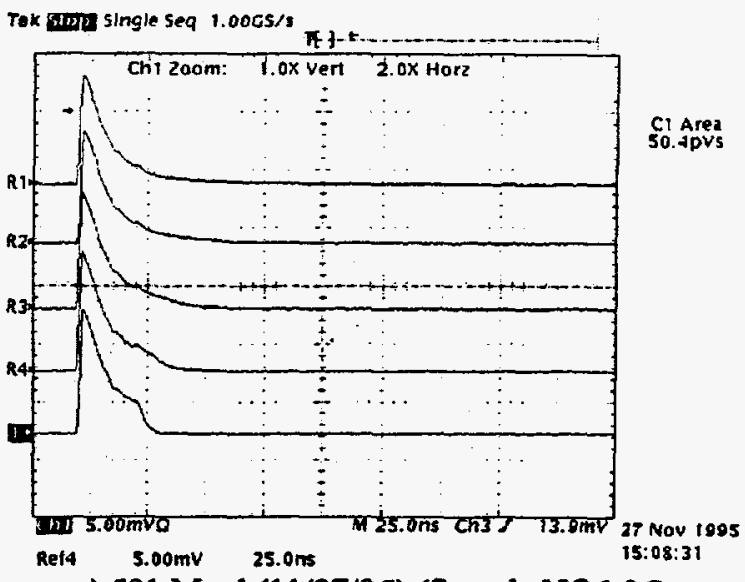

c) $501 \mathrm{Mrad}(11 / 27 / 95)$ (Sample NO6-96).

R1: $100 \mathrm{~V} ; \mathrm{R2}: 110 \mathrm{~V}$; R3: $120 \mathrm{~V}$; R4: $130 \mathrm{~V} ; 1: 150 \mathrm{~V}$

Fig. 2 Hole current shapes for a) a control sample; b) a sample irradiated to $215 \mathrm{Mrad}$; and c) a sample irradiated to $501 \mathrm{Mrad}$.

However, the annealing behavior for $\gamma$ irradiated bigh resistivity detectors are different from that for fast neutron irradiated high resistivity detectors. Fig. 3 shows the charge collection as a function of reverse bias $(Q-V)$ for a detector before and after irradiation and after elevated temperature 
annealing (ETA). In theses measurements, laser light was on the low field side and the full charge was collected at full depletion ( $Q / Q_{0}=1$ at $\left.V=V_{d}\right)$. After annealed at $110^{\circ} \mathrm{C}$ for 15 minutes (equivalent of 1-year room temperature $\left(24^{\circ} \mathrm{C}\right.$ ) anneal), $V_{d}$ is almost unchanged. Longer annealing at this temperature makes $V_{d}$ to decrease. From the corresponding TCT measurements it has been observed that this decrease of $V_{d}$ was correlated with a decrease of $N_{\text {eff }}$ from negative to less negative, or a decrease of acceptor-like and/or an increase of donor-like space charges. This is expected from a normal annealing behavior and is opposite to the observed abnormal annealing (or reverse annealing) behavior in fast neutron irradiated high resistivity silicon detectors. Annealing at a higher temperature $(150 \mathrm{C})$ made $N_{\text {eff }}$ back to positive (or donor-like), which made $V_{d}$ to increase as shown in the figure. This difference is clearly consistent with the model in which defect clusters (that can be broken-up during annealing) are considered as the main source for the acceptor creation in the SCR during the anneal.

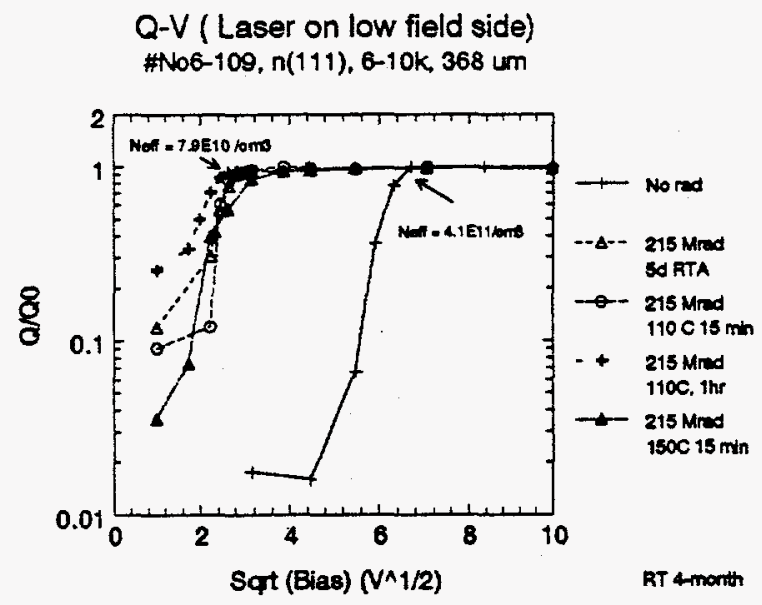

Fig. 3 Charge collection vs. reverse $(Q-V)$ bias for a detector before irradiation, after irradiation, and after annealing at temperatures shown.

Very small amount of abnormal annealing in detectors irradiated to a dose of $501 \mathrm{Mrad}$ have been observed. This data, along with the I-DLTS data in which as many as seven deep levels were found, will be presented in the full paper. Correlations between the I-DLTS data and detector electrical degradation data after irradiation and after annealing will also be made.

*This research was supported by the U. S. Department of Energy: Contract No. DE-AC02-76CH00016

\section{REFERENCES}

1. E. Borchi, M. Bruzzi, and M.S. Mazzoni, "Thermally Stimulated and Leakage Current Analysis of Neutron Irradiated Silicon Detectors", Nucl. Intrs. \& Meths., A310, pp 273, 1991.
2. A. Baldini and M. Bruzzi, "Thermally Stimulated Current Spectroscopy: Experimental Techniques for the Investigations of Silicon Detectors", Rev. Sci. Instr., Vol. 64, No. 4, pp 932, 1993.

3. C.J. $\mathrm{Li}$ and $\mathrm{Z}$. Li, "Characterization of High Fluence Neutron Induced Defect Levels in High Resistivity Silicon Detectors Using a Laser Deep Level Transient Spectroscopy (L-DLTS), BNL-49045, Nucl. Instr. \& Meth. A, Vol. 342, pp 137, 1994.

4. Z. Li, C.J. Li, V. Eremin, and E. Verbitskaya, "Investigation on the $N_{\text {eff }}$ Reverse Annealing Using TSC/I-DLTS: Relationship between Neutron Induced Microscopic Defects and Silicon Detector Electrical Degradations", BNL-61334, presented at the 7th European Symposium on Silicon Detectors, Schlob Elmau, Germany, May 7-10, 1995, to be published in Nucl. Instr. Meth.

5. C.J. $\mathrm{Li}$ and $\mathrm{Z}$. Li, "Development of Current-Based Microscopic Defect Analysis Methods and Associated Optical Filling Techniques for the Investigation on Highly Irradiated High Resistivity Silicon Detectors", BNL-61235, accepted for publication in Nucl. Instr. \& Meth. A, 1995 (in press).

6. U. Biggeri, E. Borchi, M. Bruzzi, S. Lazanu, Z. Li, and S. Lazanu; "Studies of Deep Levels in High Resistivity Silicon Detectors Iradiated by High Fluence Fast Neutrons Using a Thermally Stimulated Current Spectrometer," BNL-49017, IEEE Trans. Nucl. Sci., Vol. 41, No. 4, pp 964, 1994.

7. Z. Li, "Modelling and Simulation of Neutron Induced Changes and Temperature Annealing of $N_{e f f}$ and Changes in Resistivity in High Resistivity Silicon Detectors," BNL-49013, presented at the International Symposium on Development and Application of Semiconductor Tracking Detectors, Hiroshima, Japan, May 22-24, 1993, Nucl. Intrs. \& Meth. A, Vol. 342, pp 105, 1994.

8. Z. Li, G. Ghislotti, H.W. Kraner, C.J. Li, B. Nielsen, H. Feick, and G. Lindstroem, "Microscopic Analysis of Defects in a High Resistivity Silicon Dtector Irradiated to $1.7 \times 1015 \mathrm{n} / \mathrm{cm} 2, "$ BNL-61686, presented at the IEEE Nucl. Sci. Symp., San Francisco, CA, Oct. 21-28, 1995, to be published in IEEE Trans. Nucl. Sci., 1996 (in press).

9. V. Eremin, N. Strokan, E. Verbitskaya, and Z. Li, "The development of Transient Current and Charge Techniques for the Measurement of Effective Impurity Concentration in the Space Charge Region of p-n Junction Detectors," BNL-60156, accepted for publication in Nucl. Intrs. \& Meth., 1995 (in press).

10. Z. Li and H.W. Kraner, Modelling and Simulation of Charge Collection Properties For Neutron Irradiated Silicon Detectors; BNL-48067; Presented at the 3rd International Conference on Advanced Technology and Particle Physics, Como, Italy, 22-26 June 1992; Nucl. Phys. B, Vol. 32, pp 398-409, 